\title{
Can We Improve Outcomes in Patients With Previous Coronary Artery Bypass Surgery Admitted for Acute Coronary Syndrome?
}

Rogerio Teixeira, Carolina Lourenço, Natália António, Elisabete Jorge, Rui Baptista, Fátima Saraiva, Paulo Mendes, Sílvia Monteiro, Francisco Gonçalves, Pedro Monteiro, Mario Freitas, and Luís A. Providência

Serviço de Cardiología, Unidade de Cuidados Intensivos Coronários, Hospitais da Universidade y

Faculdade de Medicina de Coimbra, Coimbra, Portugal

Introduction and objectives. Prognosis and in-hospital management of patients with acute coronary syndrome (ACS) and a history of coronary artery bypass graft (CABG) surgery are still debated. The objective of this study was to characterize ACS patients with a CABG and to compare their in-hospital and postdischarge outcomes with those of patients without a CABG.

Methods. This ongoing prospective observational study included 1,495 consecutive patients admitted for ACS to a coronary care unit and followed up for a mean of 19 months. There were two groups: group $A(n=73)$, with CABGs; and group B $(n=1,223)$, without CABGs.

Results. Group A patients were more often male (86.3\% versus $69.1 \% ; P=.002$ ), and more frequently had a history of diabetes, myocardial infarction and heart failure. Group B patients more frequently had ST-elevation myocardial infarction, and had a higher median ejection fraction $(53 \%$ [interquartile range, 47\%-60\%] vs. 50\% [42\%-55\%]; $P<.01)$ and peak troponin-I concentration. There was no difference in the use of invasive techniques. Regarding medication, Group B patients were more likely to receive dual antiplatelet therapy at discharge. No significant difference was observed in in-hospital mortality $(9.5 \%$ versus $5.9 \% ; P=.2$ ) or mortality at 1 month, 6 months or 1 year $(9.8 \%$ versus $9.1 \%$; log-rank test, $P=.87)$ and the cumulative major adverse cardiac event rate was equally low in both groups. The presence of a CABG was associated with more readmissions for unstable angina (11.3\% vs. 3.1\%; $P<.01)$.

Conclusions. In our ACS patients, the presence of a CABG had no significant influence on short- or mediumterm outcomes, such as all-cause mortality and adverse cardiac events.

Key words: Coronary artery bypass graft. Acute coronary syndrome. Prognosis.

\section{SEE EDITORIAL ON PAGES 516-7}

Correspondence: Dr. R. Paiva Cardoso Teixeira,

Serviço de Cardiología, Hospitais da Universidade de Coimbra,

Praceta Prof. Mota Pinto, 3000 - 050 Coimbra, Portugal

E-mail: rogeriopteixeira@gmail.com

Received July 25, 2009.

Accepted for publication November 30, 2009.

\section{¿Podemos mejorar la evolución de los pacientes con antecedentes de cirugía de bypass coronario ingresados por un síndrome coronario agudo?}

Introducción y objetivos. El pronóstico y el tratamiento en el hospital de los pacientes con síndrome coronario agudo (SCA) y antecedentes de cirugía de bypass coronario (CABG) es motivo de controversia. El objetivo de este estudio es caracterizar a los pacientes con SCA que tienen antecedentes de CABG y comparar su evolución intrahospitalaria y extrahospitalaria con la de los pacientes sin antecedentes de CABG.

Métodos. Estudio prospectivo observacional continuo de 1.495 ingresos consecutivos por SCA en una misma unidad coronaria, con un seguimiento medio de 19 meses. Se dividió a los pacientes en dos grupos: grupo $A(n=73)$ con CABG previa y grupo $B(n=1.223)$ sin CABG previa.

Resultados. Los pacientes del grupo A eran con mayor frecuencia varones (el 86,3 frente al 69,1\%; $p=0,002$ ), tenían antecedentes más frecuentes de diabetes mellitus, infarto de miocardio previo e insuficiencia cardiaca. Los pacientes del grupo B tenían más infartos agudos de miocardio con elevación del ST, una fracción de eyección más alta (53\% [47\%-60\%] frente a 50\% [42\%-55\%]; $\mathrm{p}<0,01)$ y valores superiores de concentración máxima de troponina I. No se observaron diferencias en cuanto al uso de una estrategia invasiva. Por lo que respecta a la medicación, los pacientes del grupo B tenían una mayor probabilidad de recibir doble tratamiento antiagregante al alta. No se observaron diferencias significativas en cuanto a la mortalidad hospitalaria (el 9,5 frente al 5,9\%; $p=0,2$ ) ni en la mortalidad a 1 mes, 6 meses o 1 año (el 9,8 frente al 9,1\%; log-rank test, $p=0,87$ ), y la ausencia acumulativa de eventos adversos cardiovasculares mayores fue también similar en ambos grupos. Los antecedentes de $\mathrm{CABG}$ se asociaron a una mayor frecuencia de reingresos por angina inestable (el 11,3 frente al 3,1\%; $p<0,01$ ).

Conclusiones. En nuestra población con SCA, el antecedente de CABG no influyó de manera significativa en la evolución a corto y medio plazo en cuanto a la mortalidad por cualquier causa o eventos adversos cardiovasculares mayores.

Palabras clave: Bypass coronario previo. Síndrome coronario agudo. Pronósticos. 


\section{ABBREVIATIONS}

ACS: acute coronary syndrome

BMS: bare-metal stent

CABG: coronary artery bypass graft

DES: drug-eluting stent

MI: myocardial infarction

NSTEMI: non-ST-elevation myocardial

infarction

STEMI: ST-elevation myocardial infarction

UA: unstable angina

\section{INTRODUCTION}

Since its introduction in clinical practice 40 years ago, coronary artery bypass grafting (CABG) is a well-recognized treatment for stable coronary artery disease, with a major impact on survival. ${ }^{1}$

Long-term follow-up studies report $67 \%$ survival free of myocardial infarction (MI) 20 years after CABG. ${ }^{2}$ More recent data indicated an incidence of MI of $2 \%$ to $3 \%$ per year over the first 5 years, with a 5-year cumulative incidence of non-fatal MI of $15 \%,{ }^{3}$ and a recurrent infarction in as many as $36 \%$ of patients at 10 years. ${ }^{4}$ Furthermore, CABG has a positive influence on long-term quality of life and functional capacity. ${ }^{5}$

On the other hand, observational studies on acute coronary syndromes (ACS) noted an overall prevalence of $20 \%$ for patients with a history of CABG ${ }^{6,7}$

In these patients, there are 2 potential explanations, not mutually exclusive, for a new major coronary event, namely, progression of atherosclerotic disease in native arteries or the development of vascular disease in the grafts. Previous authors of an angiography study reported $8 \%$ venous graft failure at 1 year, $38 \%$ at 5 years, and $75 \%$ at 10 years after surgery, ${ }^{8}$ and progression of the atherosclerotic process in up to $51 \% 15$ years after CABG. ${ }^{9}$

The prognosis of this subset of patients, nevertheless, remains doubtful. The Thrombolysis in Myocardial Infarction (TIMI) III ACS subset registry found a similar result during the hospital stay and at 6 months; however, by 1 year the subgroup of patients with a history of CABG had a poorer prognosis (incidence of combined events, $39.3 \%$ vs $30.2 \% ; P=.002) .{ }^{10}$ Despite the poorer outcome, previous CABG was not an independent predictor of death in TIMI, ${ }^{11}$ Global Registry of
Acute Coronary Events (GRACE),${ }^{12}$ or PURSUIT ${ }^{13}$ scores. In contrast, several small series suggest a more favorable outcome for this group of patients, for both $\mathrm{MI}^{14}$ and unstable angina (UA).$^{15}$

Although no randomized studies have been designed to evaluate the benefits of an invasive versus conservative strategy in patients who have already undergone $\mathrm{CABG}$, recent guidelines recommend a low threshold for angiography with a preferable intervention in native circulation, and medical treatment similar to that used in the overall population (class I recommendation, level of evidence C). ${ }^{16}$

Due to the lack of data for this important subgroup of ACS patients when compared to others, we decided to proceed to an analysis of the in-hospital and medium-term prognosis of an unselected ACS population with previous CABG from a single center.

\section{METHODS}

A continuous, observational, prospective study of 1495 consecutive admissions for ACS between May 2004 and December 2006 was conducted in a single coronary care unit. We excluded 130 patients because they were readmissions, and an additional 33 due to incomplete data. The final population consisted of 1296 patients.

ST-elevation AMI (STEMI) was defined as ischemic chest pain associated with new onset ST elevation greater than $1 \mathrm{~mm}$ in the ECG in at least 2 contiguous leads.

Non-ST AMI (NSTEMI) was synonymous with ischemic chest pain lasting more than 5 minutes, and positive cardiac biomarkers (troponin I) with or without ECG ischemic changes (eg, ST depression or $\mathrm{T}$-wave inversion).

UA was defined as new onset angina (at least class III Canadian Cardiovascular Society [CCS]), progressive angina, or angina at rest, with or without ECG ischemic changes.

All patients gave written informed consent for participation, and the local ethics committee approved the study.

We analyzed standard records during admission, including the following data: demographic, clinical, electrical, echocardiography, laboratory, medical therapy, catheterization, in-hospital course, and discharge medication.

Median clinical follow-up after hospital discharge was 19 months. The information was collected by phone, at the outpatient clinic, or from hospital records in the event of a local repeated hospital admission. The primary endpoint was all-cause mortality and the combined result of cardiovascular death, nonfatal infarction, readmission for UA, 


\begin{tabular}{|c|c|c|c|}
\hline & A (Previous CABG) & B (No Previous CABG) & $P$ \\
\hline Number of patients & 73 & 1223 & \\
\hline Female gender & $10 / 73(13.7)$ & $378 / 1223(30.9)$ & .001 \\
\hline Mean, age (SD), y & $69.2(9.4)$ & $66.9(12.7)$ & .13 \\
\hline \multicolumn{4}{|l|}{ Admission diagnosis } \\
\hline STEMI & 6/69 (8.7) & $431 / 1183(36.4)$ & $<.001$ \\
\hline NSTEMI & $41 / 69(59.4)$ & $518 / 1183(43.8)$ & .01 \\
\hline UA & 20/69 (29.0) & $199 / 1183(1.8)$ & .01 \\
\hline Undetermined pattern & $2 / 69(2.9)$ & $35 / 1183(3.0)$ & .98 \\
\hline \multicolumn{4}{|c|}{ Risk factors for cardiovascular disease } \\
\hline Diabetes & 29/71 (40.8) & $346 / 1208(28.6)$ & .028 \\
\hline Dyslipidemia & $53 / 68(77.9)$ & $803 / 1123(71.5)$ & .25 \\
\hline Hypertension & $55 / 70(78.6)$ & $808 / 1135$ (71.2) & .18 \\
\hline Smoker & $6 / 73(8.2)$ & $234 / 1223(19.1)$ & .02 \\
\hline \multicolumn{4}{|l|}{ Cardiovascular history } \\
\hline History of infarction & $32 / 55(58.2)$ & $172 / 1095(15.7)$ & $<.001$ \\
\hline History of $\mathrm{PCl}$ & $14 / 65(21.5)$ & $109 / 1184(9.2)$ & .001 \\
\hline History of heart failure & $2 / 23(8.7)$ & $11 / 493(2.2)$ & .053 \\
\hline \multicolumn{4}{|l|}{ Previous therapy } \\
\hline ASA & 45/57 (78.9) & $274 / 729(37.6)$ & $<.001$ \\
\hline Other antiplatelets & $9 / 57(15.8)$ & $108 / 729(14.8)$ & .84 \\
\hline Beta blockers & $24 / 57(42.1)$ & $163 / 729(22.4)$ & .001 \\
\hline ACE inhibitors & $28 / 57(49.1)$ & $302 / 729$ (41.4) & .26 \\
\hline Statins & $31 / 57(54.4)$ & $217 / 729(29.8)$ & $<.001$ \\
\hline Diuretics & $15 / 57(26.3)$ & $172 / 729(23.6)$ & .64 \\
\hline Nitrates & $20 / 57(35.1)$ & $142 / 729(19.5)$ & .005 \\
\hline
\end{tabular}

ACE inhibitors indicates angiotensin converting enzyme inhibitors; ASA, acetylsalicylic acid; NSTEMI, non-ST-elevation myocardial infarction; PCl, percutaneous coronary intervention; STEMI, ST-elevation myocardial infarction; UA, unstable angina.

Values are shown as n/NNo. (\%) or mean (SD).

and percutaneous coronary intervention as major adverse cardiac events (MACE). We also recorded MI, readmission for heart failure, and stroke.

\section{Statistical Analysis}

Continuous data are presented as the median [interquartile range] and compared using the MannWhitney test, or as the mean [SD], and compared using the Student $t$ test. Categorical variables are reported as frequencies and percentages, and the $\chi 2$ test or the exact Fisher test was used when appropriate.

The cumulative survival curves were constructed using the Kaplan-Meier methods, and the groups were compared by the log-rank test. The observational period started at hospital discharge and ended 1 year after the ACS.

A Cox regression analysis was performed for the clinical endpoint of UA 1 year after the ACS. The variables included in the model were significant at $P$ less than .05 in the univariate analysis and included a history of CABG, diabetes, age over 75 years, STEMI, left ventricular ejection fraction (LVEF) lower than $40 \%$, and invasive strategy.
All statistical tests were 2-tailed, and a $P$ less than .05 was considered significant. All analyses were performed using SPSS 15 (Statistical Package for Social Sciences, SPSS Inc, Chicago, Illinois, United States).

\section{RESULTS}

The population was divided into 2 groups based on a history of CABG. Group A included 73 patients with previous CABG and group B, 1223 with no previous history of myocardial revascularization surgery.

\section{Baseline Characteristics}

The study cohort included 908 men and 388 women with a mean age of 67.0 (12.6) years; 5.6\% had a history of CABG.

Thebaselinedemographicandclinicalcharacteristics of both groups are shown in Tables 1 and 2 .

Patients with a history of CABG were more likely to be male, more often admitted for NSTEMI and $\mathrm{UA}$, and more likely to have a history of diabetes, previous infarction, and PCI. 


\begin{tabular}{|c|c|c|c|}
\hline & A (Previous CABG) & B (No Previous CABG) & $P$ \\
\hline \multicolumn{4}{|l|}{ Hemodynamic data on admission } \\
\hline Heart rate, bpm & $70[63-80]$ & 72 [61-83] & .028 \\
\hline Systolic blood pressure, $\mathrm{mmHg}$ & $136[120-150]$ & $137[120-160]$ & .42 \\
\hline Diastolic blood pressure, $\mathrm{mmHg}$ & $70[63-80]$ & $72[61-83]$ & .92 \\
\hline \multicolumn{4}{|l|}{ Killip-Kimball } \\
\hline Class I & $58 / 66(87.9)$ & $990 / 1176$ (84.2) & .42 \\
\hline Class II & $6 / 66(9.1)$ & $151 / 1176(12.8)$ & .37 \\
\hline Class III & $1 / 66(1.5)$ & $18 / 1176(1.5)$ & .99 \\
\hline Class IV & $0 / 66(0)$ & $17 / 1176(1.4)$ & .96 \\
\hline \multicolumn{4}{|l|}{ TIMI risk score } \\
\hline$\leq 2$ & $8 / 73(11.0)$ & $589 / 1233(47.8)$ & $<.001$ \\
\hline $3-4$ & $33 / 73(45.2)$ & $527 / 1233(42.7)$ & .67 \\
\hline$\geq 5$ & $32 / 73(43.8)$ & $117 / 1233(9.5)$ & $<.001$ \\
\hline LVEF & $50[42-55]$ & 53 [46.75-60] & .006 \\
\hline Body mass index, $\mathrm{kg} / \mathrm{m} 2$ & $26.5[24.8-28.3]$ & $27.2[24.5-29.4]$ & .44 \\
\hline \multicolumn{4}{|l|}{ Electrical data on admission } \\
\hline Sinus rhythm & $61 / 71(85.9)$ & $1061 / 1223(87.8)$ & .63 \\
\hline $\mathrm{AF}$ & $3 / 71(4.2)$ & $104 / 1028(8.6)$ & .20 \\
\hline T-wave inversion & $12 / 71(16.9)$ & $207 / 1208(17.1)$ & .96 \\
\hline ST depression & $12 / 71(16.9)$ & $121 / 1028(10.0)$ & .065 \\
\hline LBBB & 9/71 (12.7) & $51 / 1208(4.2)$ & .001 \\
\hline \multicolumn{4}{|l|}{ Laboratory data } \\
\hline Peak troponin I, U/L & $6.9[1.8-21.3]$ & $15.6[3.8-53.8]$ & .001 \\
\hline Peak CK-MB, U/L & $20.5[4.0-59.5]$ & $54.3[12.0-173.5]$ & .001 \\
\hline $\mathrm{LDL}-\mathrm{C}, \mathrm{mg} / \mathrm{dL}$ & $117[90-144]$ & $125[105-150]$ & .36 \\
\hline Glomerular filtration rate, $\mathrm{mL} / \mathrm{min}$ & $66[43-77]$ & $70[50-91.25]$ & .078 \\
\hline Blood glucose at admission, $\mathrm{mg} / \mathrm{dL}$ & 140 [106-182] & 129 [108-175] & .73 \\
\hline Hemoglobin at admission, $\mathrm{g} / \mathrm{dL}$ & $13.6[12.5-14.7]$ & $13.9[12.6-15.0]$ & .37 \\
\hline Minimum hemoglobin, $\mathrm{g} / \mathrm{dL}$ & $12.5[10.7-13.3]$ & $12.3[10.9-13.3]$ & .86 \\
\hline
\end{tabular}

AF indicates atrial fibrillation; CABG, coronary artery bypass graft; CK-MB, creatine kinase MB; LBBB, left bundle branch block; LDL-C, low-density lipoprotein cholesterol; LVEF, left ventricular ejection fraction; TIMI, Thrombolysis in Myocardial Infarction.

Values are shown as $n(\%)$ or mean [interquartile range].

Left bundle-branch block and a higher TIMI risk score were more frequently associated with a history of CABG, as was a lower LVEF $(50.0 \%$ [42.0\%-55.0\%] vs $53.0 \%$ [46.75\%-60\%], $P<.001)$. In contrast, a higher peak troponin I was present in group B patients.

\section{Previous History}

The present ACS that prompted inclusion in the study occurred a median of 9 (4-12.5) years after CABG. Multivessel coronary artery disease was the most frequent coronary anatomic abnormality before surgery, and $13 \%$ and $37 \%$ of patients had lesions in the left main artery and proximal left anterior descending artery, respectively.

Arterial bypasses (only mammary internal bypass were performed) were more common than venous bypasses, and $83.3 \%$ of patients were treated by both types. Triple $(38.9 \%)$ and double $(37.0 \%)$ bypasses were the most common option (Table 3). All patients were operated with classic on-pump surgery.

\section{In-Hospital Management}

An invasive strategy was used in $38(52.1 \%)$ CABG patients, compared to $732(59.9 \%)$ nonCABG patients. Despite these absolute differences, both groups had a similar probability of receiving invasive treatment. There were no significant differences regarding medical treatment during the first 24 hours (Table 4).

Regarding catheterization laboratory data after admission for ACS, patients with a history of CABG had, as expected, more extensive coronary involvement (Table 5).

In $50 \%$ of patients with previous CABG, we concluded that graft lesions were contributing to the ACS. PCI was performed in $73.2 \%(460 / 628)$ of patients with no history of CABG, compared to $47.1 \%$ 


\section{TABLE 3. Previous Surgical History}

\section{CABG Patients}

Time after surgery, $y$

1-vessel coronary disease before $\mathrm{CABG}$

2-vessel coronary disease before CABG

3-vessel coronary disease before $C A B G$

Left main artery disease before $C A B G$

Proximal $L A D$ disease before $C A B G$

Arterial bypass

Saphenous bypass

Arterial and venous bypass

1 bypass

2 bypasses

3 bypasses

4 bypasses

On-pump time, min

LVEF at time of CABG, \%

ACABG indicates coronary artery bypass graft; LAD, left anterior descending artery; LVEF, left ventricular ejection fraction.

Data are expressed as $\mathrm{n}(\%)$ or median [interquartile range].
$(16 / 34)$ of those who did ( $P=.001)$. Group B patients were also more likely to be fully revascularized and treated with a stent. Nevertheless, the odds for receiving a drug-eluting stent (DES) were similar in both groups. No patient in group A underwent a second surgical revascularization procedure.

We analyzed 55 venous grafts in the 38 patients admitted for an invasive procedure. There were $54.2 \%$ total occlusions, and most lesions were in the ostial and proximal segments of the grafts. In the case of arterial bypass grafts, a total of 30 grafts were analyzed. Significant atherosclerotic lesions were identified in only 6; half of these also had total occlusions.

PCI was performed in 7 patients in the venous grafts (Table 6).

Despite the lower rate of dual antiplatelet therapy, at discharge there were no other differences between groups with regard to aspirin, statin, ACE inhibitor, or beta blocker therapy.

TABLE 4. In-Hospital Management

\begin{tabular}{|c|c|c|c|c|c|c|}
\hline & \multicolumn{3}{|c|}{ First 24 Hours } & \multicolumn{3}{|c|}{ Medication at Discharge } \\
\hline & Previous CABG $(n=73)$ & No Previous CABG $(n=1223)$ & $P$ & Previous CABG & No Previous CABG & $P$ \\
\hline GP Ilb/Illa inhibitors & 39 (53.4) & $589(48.2)$ & .38 & & & \\
\hline Diuretics & $28(38.4)$ & $361(29.5)$ & .11 & & & \\
\hline ASA & $70(95.9)$ & $1171(95.7)$ & .95 & $64(87.7)$ & 1070 (87.5) & .96 \\
\hline Clopidogrel & $48(65.8)$ & $828(67.7)$ & .73 & $27(37)$ & 602 (49.2) & .042 \\
\hline Beta-blockers & $58(79.5)$ & $973(79.6)$ & .98 & $58(79.5)$ & $934(76.4)$ & .55 \\
\hline ACE inhibitors & $66(90.4)$ & 1091 (89.2) & .75 & $62(84.9)$ & $1050(85.9)$ & .83 \\
\hline Statins & $72(98.6)$ & $1192(97.5)$ & .53 & $66(90.4)$ & $1162(95.0)$ & .087 \\
\hline Calcium channel blockers & $9(12.3)$ & $82(6.7)$ & .07 & & & \\
\hline Nitrates & $35(47.9)$ & $465(38)$ & .09 & & & \\
\hline
\end{tabular}

ACE inhibitors indicates angiotensin-converting enzyme inhibitors; ASA, acetylsalicylic acid; CABG, coronary artery bypass graft; GP, glycoprotein.

Data are expressed as $\mathrm{n}(\%)$ or median [interquartile range].

TABLE 5. Catheterization Laboratory Data

\begin{tabular}{lcccr}
\hline & A (Previous CABG) & B (No previous CABG) & OR (95\% Cl) & P \\
\hline Primary PCI & $5 / 5(100)$ & $305 / 329(92.7)$ & & .53 \\
Invasive strategy & $38 / 73(52.1)$ & $732 / 1233(59.9)$ & $0.84(0.65-1.1)$ & .19 \\
1-vessel coronary disease & $8 / 38(21.1)$ & $311 / 732(42.5)$ & $0.36(0.16-0.8)$ & .009 \\
2-vessel coronary disease & $6 / 38(15.8)$ & $169 / 732(23.1)$ & $0.63(0.26-1.52)$ & .29 \\
3-vessel coronary disease & $23 / 38(61)$ & $141 / 732(19.3)$ & $4.19(2.16-8.13)$ & $<.001$ \\
Left main artery & $4 / 38(10.5)$ & $28 / 732(3.8)$ & $2.96(0.98-8.91)$ & .067 \\
Arterial bypass & $6 / 38(15.8)$ & 0 & & \\
Saphenous bypass & $13 / 38(34.2)$ & 0 & & \\
PCl & $16 / 34(47.1)$ & $460 / 628(73.2)$ & $0.33(0.16-0.65)$ & .001 \\
Fully revascularized & $7 / 34(20.6)$ & $312 / 628(49.7)$ & $0.26(0.11-0.61)$ & .001 \\
Partially revascularized & $9 / 34(26.5)$ & $148 / 628(23.6)$ & $1.17(0.53-2.56)$ & .70 \\
Not revascularized & $18 / 34(52.9)$ & $168 / 628(26.8)$ & $3.08(1.54-6.18)$ & .001 \\
Stent & $15 / 38(39.5)$ & $442 / 732(60.4)$ & $0.43(0.22-0.83)$ & .011 \\
Drug-eluting stents & $11 / 15(73.3)$ & $302 / 442(68.3)$ & $1.26(0.39-4.02)$ & .70 \\
Surgical revascularization & 0 & $44 / 1091(4)$ & & \\
\hline
\end{tabular}

$\mathrm{CABG}$ indicates coronary artery bypass graft; $\mathrm{Cl}$, confidence interval; $\mathrm{OR}$, odds ratio; $\mathrm{PCl}$, percutaneous coronary intervention.

Data are expressed as $n(\%)$ 
TABLE 6. Graft Lesions and Saphenous Graft PCI

\begin{tabular}{|c|c|c|c|c|c|c|c|c|}
\hline Patients & Venous Lesion & Stent & $\begin{array}{l}\text { Stent } \\
\text { Type }\end{array}$ & $\begin{array}{l}\text { Direct } \\
\text { Stenting }\end{array}$ & Diameter & Length & $\begin{array}{c}\text { TIMI } \\
\text { Flow Before }\end{array}$ & $\begin{array}{c}\text { TIMI } \\
\text { Flow After }\end{array}$ \\
\hline 1 & $99 \%$ stenosis occlusion & Yes & Cypher & No & 3 & 39 & 1 & 2 \\
\hline 2 & Two 75\% proximal stenoses (intraluminal thrombus) & Yes & Taxus (2) & Yes & $4(4)$ & $12(20)$ & 1 & 3 \\
\hline 3 & $99 \%$ proximal stenosis (intraluminal thrombus) & Yes & Cypher & No & 3 & 20 & 1 & 3 \\
\hline 4 & $75 \%$ in-stent distal restenosis & No (balloon) & & & & & 1 & 2 \\
\hline 5 & $99 \%$ medial stenosis & Yes & BMS & Yes & 4 & 23 & 1 & 3 \\
\hline 6 & $75 \%$ proximal stenosis & No (balloon) & & & & & 2 & 3 \\
\hline 7 & 99\% proximal stenosis & Yes & BMS & No & 3 & 19 & 2 & 3 \\
\hline
\end{tabular}

BMS indicates bare metal stent; PCI, percutaneous coronary intervention; TIMI, Thrombolysis in Myocardial Infarction.

Total number of venous bypass, 54; venous bypass with lesions, 24 ; total occlusion, $54.2 \%$; ostial lesions, $41.2 \%$; proximal lesions, $37.5 \%$; distal lesions, $12.5 \%$; total number of arterial bypass, 30 ; arterial bypass with lesions, 6 ; total occlusion, $3.0 \%$.

TABLE 7. Outcomes in the Hospital and 1 Year After Discharge

\begin{tabular}{lcccc}
\hline & A (Previous CABG) & B (No Previous CABG) & OR (95\% Cl) & P \\
\hline Hospital stay, d & $5(4-6.5)$ & $5(4-6)$ & .27 \\
In-hospital mortality & $7 / 73(9.6)$ & $72 / 1223(5.9)$ & $1.70(0.75-3.83)$ & .20 \\
Overall 30-day mortality & $1 / 61(1.6)$ & $26 / 1079(2.4)$ & $0.68(0.09-5.06)$ & .70 \\
Overall 6-month mortality & $4 / 61(6.6)$ & $73 / 1079(6.8)$ & $0.98(0.34-2.74)$ & .95 \\
Overall 1-year mortality & $6 / 61(9.8)$ & $98 / 1079(9.1)$ & $1.09(0.46-2.60)$ & .84 \\
MACE at 1 year & $13 / 59(22.0)$ & $187 / 1076(17.4)$ & $1.34(0.71-2.54)$ & .37 \\
Unstable angina at 1 year & $7 / 62(11.3)$ & $34 / 1093(3.1)$ & $3.96(1.68-9.34)$ & .001 \\
Reinfarction at 1 year & $4 / 59(6.8)$ & $75 / 1079(7.0)$ & $0.97(0.34-2.76)$ & .96 \\
PCl at 1 year & $5 / 60(8.3)$ & $63 / 1088(5.8)$ & $1.48(0.57-3.83)$ & .41 \\
Heart failure at 1 year & $6 / 62(9.7)$ & $64 / 1108(5.8)$ & $1.75(0.73-4.21)$ & .21 \\
Stroke at 1 year & $1 / 62(2.5)$ & $28 / 1106(2.5)$ & $0.63(0.08-4.72)$ & .65
\end{tabular}

CABG indicates coronary artery bypass graft; $\mathrm{Cl}$, confidence interval; MACE, major adverse cardiac events; $\mathrm{OR}$, odds ratio; $\mathrm{PCl}$, percutaneous coronary intervention.

\section{Follow-up}

In-hospital mortality was similar in both groups $(9.6 \%$ vs $5.9 \% \quad P=.20)$. Loss to follow-up was $6.3 \%$; hence, data on the primary endpoint (allcause mortality at 1 year) were available for 1140 patients.

No differences in 30-day, 6-month, or 1-year all-cause mortality were detected (Figure 1B). The incidence of 1-year MACE was also similar $(22.0 \%$ vs $17.4 \%, P=.37$ ) (Figure 1A); the result was also similar for readmissions for heart failure or MI (fatal or nonfatal) (Table 7).

The 1-year readmission rate for UA was significantly higher for patients with a history of CABG $(11.3 \%$ vs $3.1 \%, P=.001)$ (Figure $1 \mathrm{C}$ ), and the results remained significant in the multivariate Cox regression analysis (hazard ratio $[\mathrm{HR}]=4.49 ; 95 \%$ confidence interval [CI], 1.7-12.1), in a model that included the following variables: previous $\mathrm{CABG}$, diabetes $(\mathrm{HR}=1.76 ; 95 \% \mathrm{CI}, 0.80-3.87)$, age over 75 years $(\mathrm{HR}=0.98 ; 95 \% \mathrm{CI}, 0.41-2.34)$, left ventricular ejection fraction lower than $40 \%(\mathrm{HR}=0.80 ; 95 \%$
CI, 0.27-2.36), and invasive strategy $(\mathrm{HR}=0.84 ; 95 \%$ CI, 0.37-1.91) (overall $\chi^{2}, 14.9$ ).

In the previous $\mathrm{CABG}$ group, an invasive strategy during the acute phase did not influence 1-year MACE (Figure 1D).

\section{DISCUSSION}

\section{Baseline Data}

We found a lower prevalence of previous CABG in our population $(5.6 \%$ ) of unselected ACS patients, in contrast with rates of $20 \%$ previously reported in observational studies, ${ }^{6,7}$ but similar to the data most recently published by the Valiant trial $(7 \%) .{ }^{17}$ In addition, it is worth noting that the prevalence of previous percutaneous revascularization was higher ( $9.6 \%$, data not shown) for the overall population, probably reflecting an overall change in the treatment of coronary artery disease

As in other published series, our patients with a history of $\mathrm{CABG}$ were older, more often male, and more likely to have diabetes and a history of 


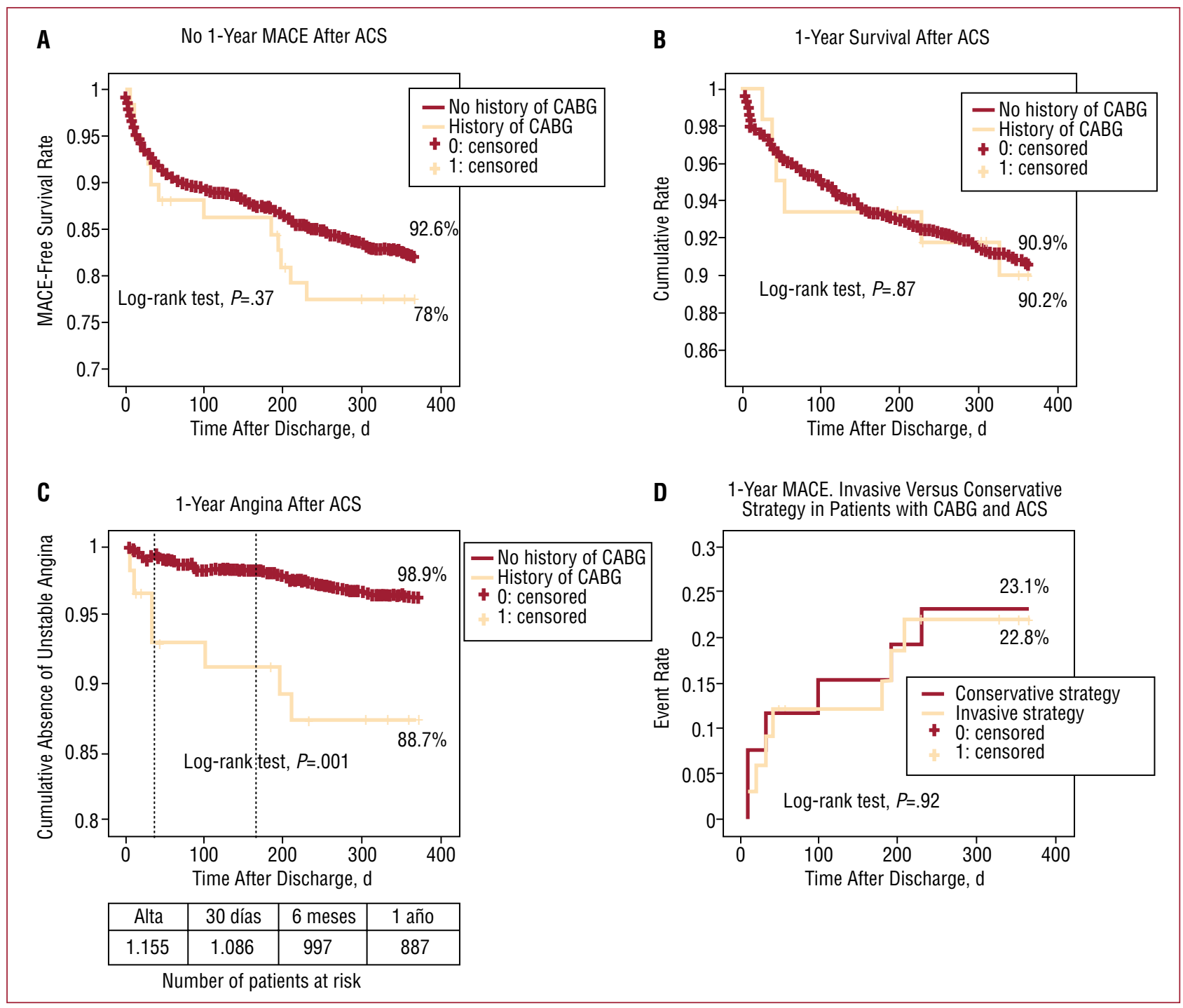

Figure. A: Kaplan-Meyer curves for cumulative MACE-free survival for ACS patients (history of CABG vs no history of CABG). B: Kaplan-Meyer curves showing overall survival for ACS patients (history of CABG vs no history of CABG). C: Kaplan-Meyer curves showing cumulative UA-free admission for ACS patients (history of CABG vs no history of CABG). D: Kaplan-Meyer curves showing 1-year MACE for patients with a history of CABG, admitted for an invasive or conservative strategy. ACS indicates acute coronary syndrome, CABG, coronary artery bypass graft; MACE, major adverse cardiac events.

PCI and MI. This could be explained by adherence to guidelines in our series regarding surgical revascularization, and by the fact that this patient subgroup has a longer history of atherosclerotic disease.

The time between CABG and the ACS was similar to that previously reported in the literature, ${ }^{18}$ and varied between a median of 4 to 12.5 years.

Patients with a history of CABG were admitted more often for a non-ST-elevation ACS and also had lower peak values of cardiac biomarkers for necrosis. This has also been previously reported and is probably related to the importance of the dual circulation (a protection mechanism for patients with ACS and a history of CABG). The protection conferred by the bypass vessels to the main coronary arteries and the more common occlusion of secondary branches as the cause of the ACS, as reported by Crean et a $1^{19}$ in 1985 , could explain this finding.

\section{Prognosis}

In our population, although a history of CABG was associated in absolute terms with a poorer outcome in terms of in-hospital and 1-year mortality, the results were not statistically different. A higher number of patients and a longer follow-up could probably have enhanced the difference and, therefore, allowed us to conclude (as other authors have $\mathrm{e}^{10,17,20-22}$ ) that patients with a history of CABG 
have a poorer outcome when they have an ACS (although a history of CABG was not an independent predictor of outcome, as assessed by the GRACE and the Valiant cohort studies). Nevertheless, we considered the following hypothesis to explain this more favorable outcome among our population with ACS and a history of CABG, when compared to previous data in the literature:

- The high prevalence of previous treatment with aspirin $(78.9 \%)$, statins, beta blockers, and ACE inhibitors $(50 \%$ in all 3 cases) before the current ACS. This rate was higher than the one published by the TIMI group,${ }^{10}$ in which only $60 \%$ of patients were receiving aspirin and only $20 \%$ of patients were on ACE inhibitors, but comparable to a subanalysis of the GRACE registry. ${ }^{23}$ This finding reinforces the importance of the long-term protective effect achieved with these 4 drug classes.

- Adherence to medical treatment guidelines were quite high in our patient subgroup, both in-hospital and at discharge, with higher levels compared to the European Heart Surveys in 2004. ${ }^{24}$

- Another important aspect of our analysis was aggressive antiplatelet therapy (53.4\%), especially with GP IIb/IIIa inhibitors. Only $19 \%$ of the Valiant trial population with a history of $\mathrm{CABG}$ were offered GP IIb/IIIa. ${ }^{17}$ We believe these drugs are a crucial treatment for dealing with unstable coronary lesions, regardless of the culprit lesion, as previously reported by the subgroup analysis of the PRISMPLUS and PURSUIT trial. ${ }^{21}$

- Similar rate of primary PCI between groups. In the Valiant trial, only $14 \%$ of patients with a history of CABG underwent PCI.

\section{Revascularization}

Almost $50 \%$ of patients with a history of CABG received an invasive strategy in the hospital, and most interventions were performed in native vessels with DES. In particular, there were multiple anatomic possibilities for the culprit lesion in these patients, and the ECG may not be that helpful in defining the location of the ischemia. Therefore, the decisions regarding revascularization in CABG were difficult, as the harm from a percutaneous intervention (especially because we were dealing with a complex lesion) could upset the delicate balance of native versus graft circulation. According to the data from a GRACE substudy, published by Gurfinkel et al, ${ }^{23}$ on the benefits of a conservative versus invasive strategy for the patient subgroup with a history of CABG, there was no benefit based on the 6-month adjusted data, and a greater proportion of patients in the invasive group required unscheduled and therapeutic invasive procedures, which meant that revascularization leads to further revascularization (although angiographic data on the coronary lesions were not reported).

Moreover, data on percutaneous revascularization of saphenous venous grafts are still debated. The literature reports on randomized studies comparing stents versus balloon angioplasty for saphenous vein stenosis, which showed no statistical difference in restenosis during a 6-month period, but with an improved clinical outcome for elective stenting. ${ }^{25}$ A recent Spanish study on 237 saphenous graft stenoses treated by DES or bare-metal stent (BMS) concluded a similar 30-month prognosis for both groups. ${ }^{26}$ Another study analyzed outcomes after PCI for patients with a history of CABG versus no history of $\mathrm{CABG}$ found that post-CABG patients had higher levels of event at 6 months, including death and MI, an outcome that was poorer for percutaneous transluminal coronary angioplasty (PTCA) in grafts versus native lesions. This poorer outcome could not be explained only by the patients' baseline characteristics, but also because graft PCI was difficult and the lesions were complex and contained more luminal thrombi. ${ }^{27}$ In a recent retrospective study by Lei Ge et al, ${ }^{28}$ the benefits of PCI with a DES vs. BMS were established for venous graft stenoses (6-month MACE-free survival of $88.5 \%$ for DES vs $71.9 \%$ for BMS), and the use of BMS was an independent predictor of MACE. In this study, the authors reported a low rate of total occlusions, only $4.3 \%$ for DES and $3.3 \%$ for BMS, and distal protection devices were used in a third of patients. In contrast, data from a randomized trial (with angiographic control) that compared sirolimus DES with BMS for similar lesions found significant benefit for DES regarding in-stent loss and target vessel revascularization, but with no major difference for the clinical endpoints. ${ }^{29}$ In this trial, patients with left ventricular dysfunction, renal impairment, and totally occluded graft lesions were excluded. Despite these benefits, a recent retrospective study for DES in saphenous grafts used in actual clinical practice reported a high rate of adverse events at 1 year, and the authors identified 2 independent predictors of adverse events (death and infarction at 1 year): luminal thrombus and the length of the stented segment..$^{30} \mathrm{~A}$ meta-analysis comparing DES vs BMS for saphenous grafts showed a lower incidence of major adverse cardiac events in the DES group over a 6- to 12-month period, mainly due to a reduction in target vessel revascularization. ${ }^{31}$ Nevertheless, there is a paucity of data on PCI in grafts, whether in a stable or unstable condition, and few randomized trials of insufficient power and short-term followup.

In our previous subgroup of patients with ACS and a history of CABG, we chose full adherence to 
medical treatment guidelines, as well as percutaneous revascularization whenever technically feasible, preferably in native vessels with a DES, based on previously reported data. Our venous grafts presented a very high proportion of total occlusion ("real world") that limited PCI. In addition, no patients underwent a second surgical revascularization.

Finally, a history of CABG was an independent predictor for a future readmission for unstable angina. This fact could have been related to more severe ischemia that probably was not amenable to revascularization, but curiously was not synonymous with a poorer medium-term prognosis. We believe, therefore, that this cohort of ACS patients represented a good example of the longterm benefit of ischemic preconditioning and the collateral circulation which is the natural course of long-term atherosclerotic disease process.

\section{Limitations}

Our study included a small number of patients with ACS and a history of CABG ACS. We compared 2 groups that had important baseline differences, and the statistical results could be misleading because the study was underpowered (power of 35.5\% for inhospital mortality, 3.6\% for 1-year mortality, $12.3 \%$ for 1-year MACE, and 50\% for readmission due to UA). However, we had no data on medication during follow-up, and the observational period was limited to 12 months. Lastly, $6.3 \%$ of patients were lost to follow-up.

\section{CONCLUSIONS}

In our study population, a history of CABG was an independent predictor of hospital readmission for UA 1 year after the ACS, although it did not significantly influence survival or other ischemic endpoints in the short or medium term. These data stress the need for aggressive medical treatment in this high-risk ACS population.

\section{REFERENCES}

1. Enríquez-Sarano M, Tajik AJ, Schaff HV, Orszulak TA, McGoon MD, Bailey KR, et al. Echocardiographic prediction of left ventricular function after correction of mitral regurgitation: results and clinical implications. J Am Coll Cardiol. 1994;24:1536-43.

2. Starling MR, Kirsh MM, Montgomery DG, Gross MD. Impaired left ventricular contractile function in patients with long-term mitral regurgitation and normal ejection fraction. $\mathbf{J}$ Am Coll Cardiol. 1993;22:239-50.

3. Starling MR. Effects of valve surgery on left ventricular contractile function in patients with long-term mitral regurgitation. Circulation. 1995;92:811-8.
4. Matsumura T, Ohtaki E, Tanaka K, Misu K, Tobaru T, Asano $\mathrm{R}$, et al. Echocardiographic prediction of left ventricular dysfunction after mitral valve repair for mitral regurgitation as an indicator to decide the optimal timing of repair. J Am Coll Cardiol. 2003;42:458-63.

5. Raymond Lee, Marwick TH. Assessment of subclinical left ventricular dysfunction in asymptomatic mitral regurgitation. Eur J Echocardiogr. 2007:8:175-84.

6. Enríquez-Sarano M, Schaff HV, Orszulak TA, Bailey KR, Tajik AJ, Frye RL. Congestive heart failure after surgical correction of mitral regurgitation. A long-term study. Circulation. 1995;92:2496-503.

7. de Isla LP, de Agustín A, Rodrigo JL, Almería C, del Carmen Manzano M, Rodríguez E, et al. Chronic mitral regurgitation: A pilot study to assess preoperative left ventricular contractile function using speckle-tracking echocardiography. J Am Soc Echocardiogr. 2009;22:831-8.

8. Perk G, Tunick PA, Kronzon I. Non-doppler two-dimensional strain imaging by echocardiography- From technical considerations to clinical applications. J Am Soc Echocardiogr. 2007;20:234-43.

9. Lee R, Hanekom L, Marwick TH, Leano R, Wahi S. Prediction of subclinical left ventricular dysfunction with strain rate imaging in patients with asymptomatic severe mitral regurgitation. Am J Cardiol. 2004;94:1333-7.

10. Jacobs LD, Salgo IS, Goonewardena S, Weinert L, Coon P, Bardo D, et al. Rapid quantification of left ventricular volume from real-time three-dimensional echocardiographic data. Eur Heart J. 2006;27:460-8

11. Vahanian A, Baumgartner H, Bax J, Butchart E, Dion R, Filippatos G, et al. Task Force on the Management of Valvular Hearth Disease of the European Society of Cardiology; ESC Committee for Practice Guidelines. Guidelines on the management of valvular heart disease: The Task Force on the Management of Valvular Heart Disease of the European Society of Cardiology. Eur Heart J. 2007;28:230-68.

12. Enríquez-Sarano M, Tajik AJ, Schaff HV, Orszulak TA, Bailey KR, Frye RL. Echocardiographic prediction of survival after surgical correction of organic mitral regurgitation. Circulation. 1994;90:830-7.

13. Enríquez-Sarano M, Schaff HV, Orszulak TA, Tajik AJ, Bailey KR, Frye RL. Valve repair improves the outcome of surgery for mitral regurgitation. A multivariate analysis. Circulation. 1995;91:1022-8.

14. Lee EM, Shapiro LM, Wells FC. Superiority of mitral valve repair in surgery for degenerative mitral regurgitation. Eur Heart J. 1997;18:655-63.

15. Enríquez-Sarano M, Avierinos JF, Messika-Zeitoun D, Detaint D, Capps M, Nkomo V, et al. Quantitative determinants of the outcome of asymptomatic mitral regurgitation. $\mathrm{N}$ Engl $\mathrm{J}$ Med. 2005;352:875-83.

16. Ling LH, Enríquez-Sarano M, Seward JB, Orszulak TA, Schaff HV, Bailey KR, et al. Early surgery in patients with mitral regurgitation due to flail leaflets: a long-term outcome study. Circulation. 1997;96:1819-25.

17. Pai RG, Bansal RC, Shah PM. Doppler-derived rate of left ventricular pressure rise: its correlation with postoperative left ventricular function in mitral regurgitation. Circulation. 1990;82:514-20.

18. Zile MR, Gaasch WH, Carroll JD, Levine HJ. Chronic mitral regurgitation: predictive value of pre-operative echocardiographic indexes of left ventricular function and wall stress. J Am Coll Cardiol. 1984;3:235-42.

19. Lee R, Haluska B, Leung DY, Case C, Mundy J, Marwick $\mathrm{TH}$. Functional and prognostic implications of left ventricular contractile reserve in patients with asymptomatic severe mitral regurgitation. Heart. 2005;91:1383-4.

20. Leung DY, Griffin BP, Stewart WJ, Cosgrove DM 3rd, Thomas JD, Marwick TH. Left ventricular function after valve repair for chronic mitral regurgitation: predictive value 
of preoperative evaluation of contractile reserve by exercise echocardiography. J Am Coll Cardiol. 1996;28:1198-205.

21. Leung DY, Armstrong G, Griffin BP, Thomas JD, Marwick TH. Latent left ventricular dysfunction in patients with mitral regurgitation: feasibility of measuring diminished contractile reserve from a simplified model of noninvasively derived left ventricular pressure-volume loops. Am Heart J. 1999;137:42734.

22. Agricola E, Bombardini T, Oppizzi M, Margonato A, Pisani $M$, Melisurgo $G$, et al. Usefulness of latent left ventricular dysfunction assessed by bowditch treppe to predict stressinduced pulmonary hypertension in minimally symptomatic severe mitral regurgitation secondary to mitral valve prolapse. Am J Cardiol. 2005;95:414-7.

23. Weidemann F, Jamal F, Sutherland GR, Claus P, Kowalski M, Hatle L, et al. Myocardial function defined by strain rate and strain during alterations in inotropic states and heart rate. Am J Physiol Heart Circ Physiol. 2002;283:792-9.

24. Edvardsen T, Helle-Valle T, Smiseth OA. Systolic dysfunction in heart failure with normal ejection fraction: Speckle-tracking echocardiography. Prog Cardiovasc Dis. 2006;49:207-14.

25. Amundsen BH, Helle-Valle T, Edvardsen T, Torp H, Crosby J, Lyseggen E, et al. Noninvasive myocardial strain measurement by Speckle tracking echocardiography. Validation against sonomicrometry and tagged magnetic resonance imaging. J Am Coll Cardiol. 2006;47:789-93.

26. Korinek J, Wang J, Sengupta PP, Miyazaki C, Kjaergaard $\mathrm{J}$, McMahon E, et al. Two-dimensional strain - a Dopplerindependent ultrasound method for quantitation of regional deformation: validation in vitro and in vivo. $\mathrm{J}$ Am Soc Echocardiogr. 2005;18:1247-53.

27. Korinek J, Kjaergaard J, Sengupta PP, Yoshifuku S, McMahon EM, Cha SS, et al. High spatial resolution speckle tracking improves accuracy of 2-dimensional strain measurements: an update on a new method in functional echocardiography. J Am Soc Echocardiogr. 2007;20:165-70.

28. Langeland S, D'Hooge J, Wouters PF, Leather HA, Claus $\mathrm{P}$, Bijnens $\mathrm{B}$, et al. Experimental validation of a new ultrasound method for the simultaneous assessment of radial and longitudinal myocardial deformation independent of insonation angle. Circulation. 2005;112:2157-62.

29. Amundsen BH, Helle-Valle T, Edvardsen T, Torp H, Crosby J, Lyseggen E, et al. Noninvasive myocardial strain measurement by speckle tracking echocardiography: validation against sonomicrometry and tagged magnetic resonance imaging. J Am Coll Cardiol. 2006;47:789-93.

30. Becker M, Bilke E, Kühl H, Katoh M, Kramann R, Franke A, et al. Analysis of myocardial deformation based on pixel tracking in two-dimensional echocardiographic images enables quantitative assessment of regional left ventricular function. Heart. 2006;92:1102-8.

31. Serri K, Reant P, Lafitte M, Berhouet M, Le Bouffos V, Roudaut $\mathrm{R}$, et al. Global and regional myocardial function quantification by two-dimensional strain: application in hypertrophic cardiomyopathy. J Am Coll Cardiol. 2006;47:1175-81.

32. Kjaergaard J, Korinek J, Belohlavek M, Oh JK, Sogaard P, Hassager. Accuracy, reproducibility, and comparability of Doppler tissue imaging by two high-end ultrasound systems. J Am Soc Echocardiogr. 2006;19:322-8.

33. Ingul CB, Torp H, Aase SA, Berg S, Stoylen A, Slordahl SA. Automated analysis of strain rate and strain: feasibility and clinical implications. J Am Soc Echocardiogr. 2005;18:411-8.

34. Okita Y, Miki S, Ueda Y, Tahata T, Sakai T, Matsuyama $\mathrm{K}$. Comparative evaluation of left ventricular performance after mitral valve repair or valve replacement with or without chordal preservation. J Heart Valve Dis. 1993;2:159-66.

35. Westaby $S$. Preservation of left ventricular function in mitral valve surgery. Heart. 1996;75:326. 